\title{
La plataformización de la comunicación política institucional. El uso de WhatsApp por parte de las administraciones locales
}

\section{The platformization of institutional political communication. The use of WhatsApp by local administrations}

Silvia Marcos García. Universitat Jaume I de Castelló. España.

smarcos@uji.es

$[\mathrm{CV}] \mathrm{CR}^{\mathrm{C}} \mathrm{C}$

Hugo Doménech-Fabregat. Universitat Jaume I de Castelló. España.

hdomenech@uji.es

$[\mathrm{CV}] \subseteq \underline{\mathrm{G}} \underline{\mathrm{R}}$

Andreu Casero-Ripollés. Universitat Jaume I de Castelló. España.

casero@uji.es

$[\mathrm{CV}] \odot \mathrm{R}^{\mathrm{i}} \mathrm{D} \%$

Este artículo es producto del proyecto de investigación AICO/2019/154, financiado por la Conselleria de Innovación, Universidades, Ciencia y Sociedad Digital de la Generalitat Valenciana.

Cómo citar este artículo / Referencia normalizada

Marcos-García, S., Doménech-Fabregat, H. y Casero-Ripollés, A. (2021). La plataformización de la comunicación política institucional. El uso de WhatsApp por parte de las administraciones $\begin{array}{lllll}\text { locales. Revista Latina de Comunicación Social, 79, 100-125. } & \text {. }\end{array}$ https://www.doi.org/10.4185/RLCS-2021-1520

\begin{abstract}
RESUMEN
Introducción: En los últimos años, las plataformas digitales, especialmente los servicios móviles de mensajería instantánea como WhatsApp, se han convertido en instrumentos esenciales para las administraciones locales. Los cambios de hábitos de la población, más propensos a realizar sus gestiones a través de los dispositivos móviles, pero también la posibilidad que estas plataformas ofrecen para promover una comunicación directa e inmediata, han hecho que los ayuntamientos vean en ellas una vía para mejorar las relaciones con la ciudadanía. Nuestro objetivo es analizar las características, usos y funciones que las instituciones locales confieren a sus servicios móviles de mensajería instantánea para comunicarse con la ciudadanía. Metodología: Se ha realizado un análisis cualitativo mediante entrevistas en profundidad a dieciocho ayuntamientos, seleccionados en base a su número de habitantes. Resultados: Los resultados muestran una panorámica de los usos de WhatsApp por parte de las administraciones locales. Esto permite identificar las motivaciones y objetivos en su implantación, sus características en relación a sus contenidos y planificación y sus retos futuros. Conclusión y discusión: Los hallazgos de esta investigación demuestran que WhatsApp está asentado en los ayuntamientos. No obstante, su uso no es capaz de aprovechar todas
\end{abstract}


las potencialidades del entorno digital, especialmente, debido a la falta de diálogo con la ciudadanía y de una planificación estratégica sólida.

PALABRAS CLAVE: comunicación política; comunicación institucional; ayuntamientos; servicios móviles de mensajería instantánea; WhatsApp; plataformización

\begin{abstract}
Introduction: In recent years, digital platforms, especially mobile instant messaging services such as WhatsApp, have become essential tools for local administrations. Changes in the habits of the population, more likely to carry out their procedures through mobile devices, but also the possibility that these platforms offer to promote direct and immediate communication have made city councils see in them a way to improve relations with the citizens. Our objective is to analyse the characteristics, uses and functions that local institutions confer on their mobile instant messaging services to communicate with citizens. Methodology: A qualitative analysis has been carried out through in-depth interviews with eighteen municipalities, selected based on their number of inhabitants. Results: The results show an overview of the uses of WhatsApp by local administrations. This makes it possible to identify the motivations and objectives in its implementation, its characteristics in relation to its contents and planning and its future challenges. Conclusion and discussion: The findings of this research show that WhatsApp is established in the local administrations. However, its use is not capable of taking advantage of all the potentialities of the digital environment, especially due to the lack of dialogue with citizens and solid strategic planning.
\end{abstract}

KEYWORDS: political communication; institutional communication; city councils; mobile instant messaging services; WhatsApp; platformization

\title{
CONTENIDO
}

1. Introducción. 2. Objetivos. 3. Metodología. 4. Resultados. 5. Discusión y conclusiones. 6. Bibliografía

\section{Introducción}

En los últimos años, el surgimiento imparable de diferentes medios sociales ha cambiado nuestros hábitos comunicativos de una forma acelerada. Plataformas como Facebook, Twitter, YouTube o Instagram, entre otras, o los más recientes servicios móviles de mensajería instantánea como WhatsApp o Telegram, no solo se han asentado en nuestra vida cotidiana, sino que se han convertido en elementos indispensables en muchos ámbitos sociales (Plantin \& Punathambekar, 2019). La capacidad para proporcionar información de forma directa, fomentar la participación y compromiso de la ciudadanía o favorecer la imagen de transparencia de las instituciones ha hecho que las administraciones públicas locales hayan incorporado estas plataformas como instrumentos de comunicación política permanente (Criado, et al. 2017; Bimber, 2014).

Entre todas estas aplicaciones móviles, WhatsApp y Telegram han tomado una especial relevancia debido a la popularidad que han adquirido en los últimos años entre los usuarios y a la facilidad con la que permiten abordar problemas sociales que afectan directamente a la vida cotidiana de la ciudadanía (Casero-Ripollés, 2020a). En este contexto, el uso de este tipo de herramientas supone una oportunidad para que las administraciones públicas puedan potenciar el derecho a la información de la ciudadanía, fomentar la transparencia de la información pública y su actividad política y mejorar los niveles de compromiso cívico y participación política de la ciudadanía en un contexto 
marcado por una fuerte desafección y una crisis de legitimidad de la democracia representativa (Castells, 2017; Feenstra et al. 2017).

Hasta ahora, gran parte de las investigaciones previas se han centrado en conocer, por un lado, el uso general que las administraciones públicas han hecho de estas plataformas y, por otro lado, la percepción y los efectos que han tenido las mismas sobre la ciudadanía (Gil de Zúñiga, et al., 2021; Castro Martínez, et al., 2021; Castillo-Esparcia, et al., 2020; López-Tárraga, 2020; Gutiérrez-Rubí, 2015). Sin embargo, todavía se ha profundizado poco sobre las características funcionales que permiten definir este tipo de servicios móviles de mensajería instantánea en las administraciones públicas y en conocer cuáles son los objetivos de los ayuntamientos a la hora de usarlas. Para cubrir este vacío en la literatura, esta investigación plantea un análisis de los usos y las funciones asignadas a los servicios móviles de mensajería instantánea por parte de las instituciones públicas locales, asî como la identificación de sus motivaciones y objetivos a la hora de adoptar y poner en marcha este tipo de canales de comunicación con la ciudadanía.

\section{La plataformización de la comunicación política}

En los últimos años, los dispositivos móviles se han convertido en una herramienta indispensable en la vida cotidiana de la ciudadanía. En España, el 99,5\% de los hogares tiene, al menos, un teléfono móvil (INE, 2020). De estos, el 93,1\% considera este dispositivo como el preferente para acceder a Internet y el 85,8\% como vía para consultar sus redes sociales (AIMC, 2020). Plataformas como Facebook, Twitter, Instagram, YouTube, o los servicios móviles de mensajería instantánea como WhatsApp o Telegram, han crecido de forma significativa, convirtiéndose en un elemento esencial para múltiples sectores (Plantin \& Punathambekar, 2019). Pese al origen social de estas plataformas, creadas principalmente para que los usuarios compartieran intereses e información personal, la conectividad, inmediatez, portabilidad, personalización y ubicuidad de estas tecnologías están contribuyendo a redefinir el escenario comunicativo y social en un sentido amplio (Aguado \& Martínez, 2008).

Estos medios sociales se han posicionado como distribuidores y emisores de información, llegando a condicionar el núcleo mismo de los procesos democráticos o políticos (Gillespie, 2018; Van Dijck, et al., 2018). De esta forma, estas plataformas están ocupando un papel central, no solo en las interacciones sociales, sino también en los hábitos de consumo de la información e incluso, en la participación política de la ciudadanía (Gil de Zúñiga; et al., 2021). Un fenómeno que autores como Van Dijck, Poell y de Waal (2018:5) o Nieborg y Poell (2018:2) definen como "plataformización". Este concepto hace referencia a la consolidación de las plataformas digitales en nuestras vidas cotidianas, aspecto que les otorga un papel central en las dinámicas sociales. Cada vez más aspectos relacionados con el funcionamiento de la política y la sociedad dependen de las plataformas. Estas se configuran como infraestructuras clave para la transformación social que ofrecen nuevas potencialidades, y también establecen nuevos límites para la comunicación política. En este contexto, asumen un fuerte protagonismo en las prácticas sociales y políticas y adquieren la capacidad de condicionarlas decisivamente.

El fácil acceso y la posibilidad ilimitada de creación y difusión de contenidos hace de estas plataformas un lugar preferente para generar nuevas formas de interacción y fomentar la conectividad social, lo que resulta fundamental para el surgimiento de una nueva cultura participativa (Ling, 2017; Bayer, et al., 2016). Algunos autores evidencian que el uso del móvil y de estas plataformas resulta uno de los factores clave en la implicación de la ciudadanía en las actividades políticas y hacen que los usuarios más activos refuercen su conocimiento y su capacidad para intervenir en la vida pública (Lee, et al., 2014). Uno de los ejemplos más significativos donde se 
aprecian sinergias entre la participación online y offline mediante el uso de móviles se sitúa en las movilizaciones vividas en la última década, como la Primavera Árabe, el 15M en España o el movimiento Occupy Wall Street en Nueva York (Fuchs, 2014; Willnat et al., 2013; Rojas \& PuigAbril, 2009). A la vez que la ciudadanía se quejaba en la calle, utilizaba las plataformas digitales para compartir mensajes e imágenes, demostrando como la viralidad de Facebook, Twitter o WhatsApp, entre otras, puede transformar una protesta localizada en un movimiento más amplio. En estos contextos, los medios sociales permiten a las personas alzar la voz por causas compartidas y conectarse a una escala sin precedentes para perseguir objetivos democráticos (Bennett \& Segerberg, 2012).

La necesidad de las administraciones locales de ofrecer información oficial, de forma rápida y directa a sus ciudadanos ha hecho que, durante los últimos años, los ayuntamientos hayan impulsado activamente este tipo de recursos tecnológicos. Al interactuar con los grupos de ciudadanos, los gobiernos locales no solo les otorgan la posibilidad para acceder a la información pública para el ejercicio de sus derechos políticos, sino que también potencian una imagen de instituciones transparentes, funcionales y efectivas (Manfredi-Sánchez, 2017; Bertot, et al., 2010).

\subsection{El uso de medios sociales por parte de las administraciones públicas}

La incorporación de medios sociales como herramienta comunicativa en el ámbito político ha sido amplia de forma que, desde 2009 hasta hoy, numerosos ayuntamientos han hecho un uso cada vez más generalizado de las plataformas sociales (Mickoleit, 2014). Tal y como afirman diversos estudios, son muchas las administraciones públicas a nivel local o nacional, pero también a nivel internacional en otros puntos de Europa o Estados Unidos, las que ya cuentan con uno o varios perfiles en redes sociales para brindar información institucional, fomentar interacciones con los ciudadanos y mejorar su transparencia (Criado \& Villodre, 2021; Solito \& Materassi, 2020; Guillamón, et al., 2016; Graham \& Avery, 2013, Bonsón, et al., 2012). Así, ayuntamientos y otras instituciones públicas han encontrado en estas tecnologías una vía para mejorar la relación con la ciudadanía y transformar su gestión interna, convirtiéndose en entidades mucho más abiertas y transparentes (Bretschneider \& Parker, 2016). Como principales representantes de las ciudades, la comunicación llevada a cabo por estas instituciones supone un poderoso instrumento para explicar, justificar y legitimar las decisiones políticas asumidas (Campillo Alhama, 2010).

Pese a que estudios como el de Criado, Rojas-Martin y Gil-García (2017) apuntan a que el gobierno a nivel local todavía se encuentra en una etapa temprana de desarrollo de su estrategia comunicativa en redes sociales, la literatura previa demuestra que estas son una herramienta informativa útil (Solito \& Materassi, 2020). Proporcionar información, fomentar la participación y el compromiso de la ciudadanía o incrementar la transparencia de la institución son algunas de las motivaciones más significativas que determinan el uso de estas plataformas por parte de los ayuntamientos (Criado, et al., 2017; Spilotopoulou, et al., 2014). Los medios sociales permiten a las administraciones difundir de forma autónoma iniciativas y datos importantes que hasta ahora quedaban relegados a la intermediación de los medios de comunicación (Salvador \& Ramírez, 2016), potenciando, así, las relaciones de proximidad e intercambio de información entre ciudadanos. Esto se produce, especialmente, en los ayuntamientos más pequeños, con un menor volumen de población (ZurutuzaMuñoz \& García-Herrer, 2021). Por consiguiente, el contenido de la información puede activar a la población, involucrándola en acciones y servicios relacionados con su vida diaria y aumentando su compromiso cívico (Lev-On \& Steinfeld, 2015). Al mismo tiempo, la posibilidad de difundir información sobre su gestión hace que las plataformas sociales se hayan convertido en instrumentos imprescindibles para favorecer la rendición de cuentas de las administraciones públicas, cumplir con los estándares de transparencia y responsabilidad y, por tanto, recuperar la confianza de los 
ciudadanos (Van Dijck, et al., 2018; Simelio-Solà \& Rodríguez Navas, 2014; Pintado Pérez \& Paniagua Rojano, 2018).

Estas potencialidades, no obstante, se ven limitadas en muchos casos por algunos factores significativos e internos a las propias instituciones públicas. La poca de disponibilidad de recursos para el mantenimiento, control y evaluación de estas plataformas, la falta de un modelo de gestión que involucre al conjunto de la organización o el desconocimiento de algunas cuestiones relacionadas con la seguridad y la privacidad de estas tecnologías son algunas de las principales preocupaciones de los ayuntamientos a la hora de planificar una estrategia comunicativa en estos medios (Criado, et al., 2017). Pese a que la facilidad de acceso que permiten las plataformas digitales puede suponer una ventaja, especialmente, para la consulta y difusión de un gran número de contenidos, también supone un reto para las administraciones públicas debido al incremento de la circulación de bulos y engaños y a la presencia de perfiles falsos, muy difíciles de identificar y controlar (Casero-Ripollés, 2020a).

Hasta ahora, la mayor parte de la literatura previa señala que los medios sociales más populares en las estrategias comunicativas de las administraciones públicas son, principalmente, Facebook y Twitter (Solito \& Materassi, 2020; Simelio-Solà \& Rodríguez Navas, 2014). Por un lado, Facebook se ha posicionado como una plataforma práctica para crear comunidad y aumentar los niveles de compromiso de los ciudadanos con el gobierno local, especialmente cuando éste promueve acciones y publicaciones lanzadas por la ciudadanía (Reddick, et al., 2017; Bonsón, et al., 2015). En este sentido, Facebook se ha convertido en una plataforma importante en la infraestructura de información política local ya que, gracias a su mediación, los gobiernos locales están llegando directamente al público, evitando la dependencia de los medios de comunicación locales (Thorson, et al., 2020). Por otro lado, Twitter resulta un espacio útil para difundir y actualizar información de forma inmediata e, incluso, para extraer el sentimiento y la reacción del público en torno a eventos y decisiones políticas (Thelwall et al. 2011, Waters \& Williams 2011).

En los últimos años, se ha extendido el empleo de los servicios móviles de mensajería instantánea, como WhatsApp o Telegram. El uso de estas plataformas digitales en la administración pública, sin embargo, sigue sin explorar ni rentabilizar las potencialidades que derivan de este medio digital (Vázquez Sande, 2016). A pesar de que las instituciones públicas otorgan gran importancia a estos medios, todavía no se aprovechan sus características como espacios de participación y de diálogo con la ciudadanía. Por el contrario, se utilizan desde una perspectiva meramente informativa, adoptando una dinámica unidireccional (Solito \& Materassi, 2020; De Widt \& Panagiotopoulos, 2018; Criado, et al., 2017).

\subsection{Servicios móviles de mensajería instantánea en los ayuntamientos}

Los servicios móviles de mensajería instantánea como WhatsApp o Telegram se ha convertido en una nueva oportunidad para conectar las administraciones públicas, principalmente las locales, con la ciudadanía. En un contexto con una interacción limitada entre ambos actores, estas plataformas digitales permiten llegar a un mayor segmento de población, así como también poder aportar la información de una manera mucho más ágil y directa (Newman et al., 2019).

En 2021, WhatsApp es la aplicación con mayor número de usuarios en España (89,5\%), por delante de YouTube (89,3\%), Facebook (79,2\%), Instagram (69\%) o Twitter (52,6\%) (Digital, 2021). Su naturaleza permite a los usuarios intercambiar instantáneamente mensajes a través del móvil sin pagar por su envío y que sean ellos mismos los que decidan qué información difunden y a qué contacto o grupo (Bossetta, 2018). Según algunos autores, su potencial radica en que motiva el 
empoderamiento de la ciudadanía, que puede unirse en una acción colectiva, únicamente a partir del uso del smartphone (Gutiérrez-Rubí, 2015). Los grupos de WhatsApp constituyen un buen ejemplo, ya que, a partir de la iniciativa individual de una persona (quien crea y administra el grupo), otros usuarios se unen en un mismo espacio comunicativo compartido con personas con características, gustos o intereses comunes (Malka, et al., 2015). Al generar un ambiente cerrado y controlable, con mayor seguridad y privacidad que otros medios sociales, ofrece mayores incentivos a la participación política, incluso en aquellos casos de opiniones políticas extremas ideológicamente (López-Tárraga, 2020; Valeriani \& Vaccari, 2017). Por su parte, Telegram se ha convertido en la segunda aplicación de mensajería instantánea más utilizada en España. De un modo similar a WhatsApp, permite a los usuarios enviar y recibir mensajes directos de texto y multimedia sin disponer necesariamente de una conexión a Internet de gran velocidad (Fernández, 2018).

Pese a que el uso de ambas plataformas es reciente en el ámbito político, la literatura previa demuestra como ambos servicios móviles de mensajería instantánea se han configurado como un aliado para las administraciones locales, especialmente, en momentos de crisis como la vivida a causa de la COVID-19 (Casero-Ripollés, 2020a; Pérez-Curiel \& Velasco-Molpeceres, 2020). Tanto WhatsApp como Telegram han permitido a los ayuntamientos difundir información oficial y verificada, un factor clave a la hora de combatir bulos y fake news (López-Tárraga, 2020). En este sentido, ofrece a las instituciones locales una vía para convertirse en una fuente informativa principal de la ciudadanía y para generar credibilidad.

En este contexto, la mayor parte de los estudios previos se han centrado en evaluar las percepciones de la ciudadanía respecto al conjunto de los medios sociales o el empleo general que las administraciones públicas hacen de las mismas (Castro Martínez, et al., 2021; Castillo-Esparcia et al., 2020; García-Santamaría et al., 2020; Criado, et al., 2017; Gutiérrez-Rubí, 2015). Sin embargo, todavía son pocas las investigaciones específicas sobre los servicios móviles de mensajería instantánea y, específicamente, sobre cuáles son las motivaciones y objetivos de los ayuntamientos para su utilización. Por ello, el presente trabajo se plantea desde un enfoque exploratorio con el fin de profundizar en el uso que las administraciones públicas locales realizan de estas plataformas en su estrategia de comunicación.

\section{Objetivos}

El objetivo general de esta investigación es explorar las características, usos y funciones que las instituciones locales confieren a sus servicios móviles de mensajería instantánea para comunicarse con la ciudadanía. De manera concreta, se plantean tres objetivos específicos:

O1. Identificar el modo de implantación de los servicios móviles de mensajería instantánea por parte de las administraciones públicas locales, así como su estrategia de planificación en relación al tipo de contenidos, periodicidad de publicación y tipología de los mensajes.

O2. Analizar las formas de interacción que se establecen entre los ayuntamientos y la ciudadanía en estos servicios móviles de mensajería instantánea.

O3. Conocer las limitaciones y retos futuros a los que se enfrentan las administraciones públicas locales a la hora de adoptar y poner en marcha este tipo de canales móviles de mensajería instantánea.

\section{Metodología}

Para conocer el uso que las administraciones públicas locales hacen de los servicios móviles de mensajería instantánea en sus estrategias de comunicación, se ha optado por un análisis cualitativo mediante entrevistas en profundidad. El uso de esta técnica resulta adecuado especialmente para 
objetos de estudio poco explorados y vinculados a un contexto de transformaciones intensas (Karpf, et al., 2015). Tomando como caso de estudio la Comunidad Valenciana, la muestra de esta investigación comprende 18 entrevistas realizadas a responsables políticos y técnicos de comunicación de ayuntamientos de diferentes municipios. Específicamente, la selección de los municipios pretende representar las características en el uso de estas plataformas por parte de municipios con diferente número de habitantes. Así, la muestra se ha estratificado en tres tipos de ciudades en función de su número de habitantes: ayuntamientos grandes -AG- (con una población mayor de 50.000 habitantes), ayuntamientos medianos -AM- (entre 50.000 y 10.000 habitantes) y ayuntamientos pequeños -AP- (con menos de 10.000 habitantes). En total, se han incluido tres instituciones locales del primer tipo, siete del segundo y ocho del tercero para tener una representatividad adecuada al territorio estudiado (Tabla 1). Concretamente, la elección de los municipios estudiados responde a los criterios de una muestra estratégica no aleatoria articulada a partir de tres reglas: primero, la existencia y uso activo del servicio de WhatsApp por parte de los ayuntamientos; segundo, el número de habitantes del municipio para responder a las tres categorías establecidas; $y$, tercero, la accesibilidad ofrecida por las propias instituciones a la hora de realizar las entrevistas. Con el objetivo de mantener la confidencialidad de las respuestas, en la explotación de los resultados se ha mantenido su anonimato utilizando un número aleatorio para cada uno de ellos e indicando su grupo de pertenencia.

Las entrevistas en profundidad se basan en un cuestionario abierto, basado en un guion inicial de 30 preguntas estructurado en cuatro bloques. El primero incluye cuestiones relativas a la percepción y motivación en el uso de las redes sociales, en general, y de los servicios móviles de mensajería instantánea, en particular, como instrumentos de la comunicación política institucional del ayuntamiento. El segundo se centra en la funcionalidad y contenidos difundidos a través de estos servicios. El tercero incluye preguntas sobre el uso de estas plataformas digitales como vía de interacción directa con la ciudadanía. Finalmente, el cuarto se orienta hacia los retos futuros de las instituciones locales respecto a la utilización de estas aplicaciones móviles. Las entrevistas se realizaron de forma presencial y de forma telemática, a través de videollamadas o llamadas telefónicas, entre septiembre de 2020 y febrero de 2021, con una duración aproximada de entre 45 y 60 minutos. A partir de una transcripción literal del contenido de las entrevistas (verbatim) por parte de dos investigadores, se llevó a cabo un análisis temático de forma inductiva, examinando manualmente los datos y categorizando las respuestas en diferentes unidades temáticas para extraer conclusiones. Con el objetivo de mejorar la calidad y el rigor de la investigación, los resultados fueron contrastados por un tercer investigador mediante un nuevo análisis del conjunto de las entrevistas.

Tabla 1. Muestra de análisis

\begin{tabular}{|l|l|l|}
\hline Número habitantes & Municipio & Provincia \\
\hline Ayuntamientos grandes (AG) & Castellón & Castellón \\
\cline { 2 - 3 } Mayor de 50.000 habitantes & Elche & Alicante \\
\cline { 2 - 3 } & Valencia & Valencia \\
\hline Ayuntamientos medianos (AM) \\
$\begin{array}{l}\text { Entre 50.000 y 10.000 } \\
\text { habitantes }\end{array}$ & Alcora & Castellón \\
\cline { 2 - 3 } & Catarroja & Valencia \\
\cline { 2 - 3 } & Manises & Valencia \\
\cline { 2 - 3 } & Nules & Castellón \\
\cline { 2 - 3 } & Onda & Castellón \\
\cline { 2 - 3 } & Puzol & Valencia \\
\cline { 2 - 3 } & Sedaví & Valencia \\
\hline \multirow{4}{*}{$\begin{array}{l}\text { Ayuntamientos pequeños (AP) } \\
\text { Menor de 10.000 habitantes }\end{array}$} & Benejama & Alicante \\
\cline { 2 - 3 } & Bechí & Castellón \\
\cline { 2 - 3 } & Chelva & Valencia \\
\hline
\end{tabular}


RLCS, Revista Latina de Comunicación Social, 79, 100-125

[Investigación] DOI: 10.4185/RLCS-2021-1520| ISSN 1138-5820| Año 2021

\begin{tabular}{|l|l|l|}
\hline \multirow{4}{*}{} & El Puig & Valencia \\
\cline { 2 - 3 } & Foios & Valencia \\
\cline { 2 - 3 } & Morella & Castellón \\
\cline { 2 - 3 } & Sueras & Castellón \\
\cline { 2 - 3 } & Jijona & Alicante \\
\hline
\end{tabular}

Fuente: elaboración propia

\section{Resultados}

\subsection{Adaptación de la comunicación política institucional a las plataformas digitales}

Los resultados indican cómo los medios sociales y, particularmente WhatsApp, se están convirtiendo en herramientas cada vez más asentadas en las estrategias comunicativas de las administraciones locales. Tal y como se observa en la Tabla 2, actualmente el 35,05\% de los ayuntamientos valencianos ya hace un uso activo y continuado de WhatsApp dentro de sus estrategias de comunicación institucional.

Tabla 2. Uso de WhatsApp en los municipios de la Comunidad Valenciana

\begin{tabular}{|l|c|c|}
\hline & Total de municipios & Municipios con WhatsApp \\
\hline Castellón & 135 & $47(34,81 \%)$ \\
\hline Valencia & 266 & $110(41,35 \%)$ \\
\hline Alicante & 141 & $33(23,40 \%)$ \\
\hline TOTAL & $\mathbf{5 4 2}$ & $\mathbf{1 9 0}(\mathbf{3 5 , 0 5 \%})$ \\
\hline
\end{tabular}

Fuente: elaboración propia

De manera detallada, los ayuntamientos de los municipios pequeños son aquellos que han visto una mayor oportunidad en el uso de WhatsApp, ya que está presente en una media del $72,31 \%$ de los municipios de este tipo, superando el $50 \%$ en las tres provincias estudiadas (Tabla 3). Por el contrario, los municipios medianos $(\mathrm{M}=24,66 \%)$ y, especialmente los grandes $(\mathrm{M}=3,03 \%)$, todavía se encuentran en una fase de adaptación (Tabla 3). Ahora bien, cabe destacar que los ayuntamientos entrevistados, con independencia a su número de habitantes, coinciden al valorar estas plataformas como un elemento clave para la comunicación entre la institución pública y la ciudadanía. Desde una óptica positiva, los responsables de la comunicación local entrevistados apuntan a la transformación que han vivido en los últimos años, no solo por la incorporación de estas herramientas en su organización, sino también por el propio cambio en sus rutinas productivas.

Tabla 3. Uso de WhatsApp en los municipios de la Comunidad Valenciana según número de habitantes del municipio (en \%)

\begin{tabular}{|l|c|c|c|}
\hline & $\begin{array}{c}\text { Pequeños } \\
(<\mathbf{1 0 . 0 0 0} \text { hab. })\end{array}$ & $\begin{array}{c}\text { Medianos } \\
\text { (Entre 10.000 y 50.000 hab.) }\end{array}$ & $\begin{array}{c}\text { Grandes } \\
(>\mathbf{5 0 . 0 0 0} \text { hab. })\end{array}$ \\
\hline Castellón & 82,98 & 14,89 & 2,13 \\
\hline Valencia & 76,36 & 22,73 & 0,91 \\
\hline Alicante & 57,58 & 36,36 & 6,06 \\
\hline TOTAL & $\mathbf{7 2 , 3 1}$ & $\mathbf{2 4 , 6 6}$ & $\mathbf{3 , 0 3}$ \\
\hline
\end{tabular}

Fuente: elaboración propia 
Concretamente, los resultados muestran dos ideas significativas. Por un lado, la adaptación a las nuevas demandas de la ciudadanía y, por otro lado, la sustitución de las fórmulas de comunicación institucional hasta ahora establecidas. En primer lugar, en cuanto a la adaptación de las administraciones locales a las plataformas digitales, detectamos que más que por decisión propia, esta se ha producido como una respuesta a las demandas de la ciudadanía. En este sentido, los entrevistados indican que el uso de estas plataformas como parte de su estrategia de comunicación política ha derivado de los cambios en los hábitos de consumo de la ciudadanía, ahora más predispuesta a realizar sus consultas a través de sus dispositivos móviles y a utilizar este tipo de aplicaciones.

"Hemos cambiado de estrategia. Antes la web del ayuntamiento era la referencia para informarse. En cambio, ahora solo se utiliza para cuestiones puntuales. Hoy en día, los ciudadanos utilizan mayoritariamente las redes sociales" (AM9).

"Nos hemos adaptado a la forma de comunicar actual para llegar a todos los públicos" (AM80).

En este mismo sentido, encontramos una diferencia relevante en las interpretaciones de los diferentes tipos de municipios en función de su población. Mientras que los ayuntamientos con mayor número de habitantes manifiestan un balance muy positivo de su actual rol en la gestión de las plataformas digitales, los más pequeños observan esta adaptación todavía con cautela. Aunque son los tipos de municipios En su mayoría afirman no sentirse plenamente asentados en el entorno digital.

"Estamos plenamente adaptados al entorno digital. Empezamos con la página web. Después continuamos por Facebook, Twitter, WhatsApp e Instagram y, desde hace, poco hemos incorporado Telegram. Lo tenemos todo bastante bien cubierto" (AM3).

"Actualmente estamos muy encima de las redes sociales, pero nuestra adaptación a este entorno ha ido muy poco a poco" (AP21).

"La adaptación del ayuntamiento a las redes sociales lleva mucho tiempo, da vértigo" (AP27).

En segundo lugar, la incorporación de las plataformas digitales ha supuesto una modificación relevante en las prácticas comunicativas de las instituciones locales. Según indican los entrevistados, muchos ayuntamientos han visto cómo las fórmulas y recursos tradicionalmente utilizados en la comunicación política institucional se han visto desplazados por el uso de las plataformas digitales. Estas se perciben como mucho más efectivas para contactar con la ciudadanía. Una de las herramientas sustituidas ha sido el tradicional bando. Antes, gracias a la megafonía, los ayuntamientos transmitían de forma oral cualquier aviso o comunicado oficial. Ahora, en muchos casos, esa información se difunde a través de los servicios móviles de mensajería instantánea.

"Antes la nota de prensa era lo más importante. Ahora le dedicamos mucho más tiempo a las redes" (AM9).

"Años atrás, un operario del ayuntamiento iba por las calles con un megáfono e informaba a la población. Hoy, esta función la sustituyen las redes sociales, y de una forma muy positiva" (AP40).

"WhatsApp ha sustituido como medio de comunicación al bando que funcionaba mediante altavoces, el cual se mantiene ahora solo de forma testimonial" (AP45). 


\subsection{Objetivos y motivaciones de las administraciones públicas en el uso de los servicios móviles de mensajería instantánea}

Pese a que todos los ayuntamientos entrevistados afirman haberse adaptado ampliamente al contexto digital y contar con perfiles abiertos en diversas plataformas, una de las que ha tomado mayor importancia en la comunicación política institucional de los últimos años son los servicios móviles de mensajería instantánea, especialmente WhatsApp. Según los entrevistados, esta plataforma digital se ha convertido en la vía más efectiva para que las instituciones públicas puedan llegar a gran parte de su población, independientemente de su edad o intereses.

"Comenzamos con Facebook, luego Twitter, pero nos dimos cuenta que solo llega [a los usuarios] un $10 \%$ del contenido que queremos. Por eso pensamos en abrir un canal de WhatsApp" (AM90).

"WhatsApp es la herramienta más potente, el mejor canal de comunicación, el más útil, el más cómodo para los ciudadanos. El pueblo nunca ha estado mejor informado" (AM9).

De forma más concreta, los resultados de las entrevistas determinan que el uso de este servicio móvil de mensajería instantánea por parte de los ayuntamientos viene determinado por tres grandes motivaciones.

En primer lugar, la mayoría de las administraciones públicas indica que la razón principal por la que han puesto en marcha un canal de WhatsApp es la posibilidad de poder comunicarse con los ciudadanos de una forma directa e inmediata. El hecho de poder escribir personalmente y difundir sin intermediarios los mensajes en la aplicación, además de que estos lleguen automáticamente a los dispositivos móviles de sus vecinos, son uno de los principales atractivos para el uso de WhatsApp por parte de los ayuntamientos. En un contexto tradicionalmente marcado por la mediación de los periodistas, este servicio móvil de mensajería instantánea permite eliminar cualquier intermediario o barrera entre la institución y los usuarios. Esta aplicación permite ofrecer información útil y de interés para la ciudadanía prácticamente en el mismo momento en el que se produce. Por ejemplo, situaciones de emergencia, accidentes o informaciones de última hora.

Del mismo modo, la ciudadanía tiene a su alcance la posibilidad de trasladar sus dudas, advertir a las administraciones locales sobre alguna incidencia o, incluso, realizar algunas de sus gestiones sin la necesidad de acudir presencialmente al ayuntamiento. La información que tiene mayor valor para la ciudadanía es la que afecta de forma más directa a su vida cotidiana. En consecuencia, suelen referirse a aspectos que son competencia municipal. Por esta razón, y para poder vehicular estas cuestiones de manera ágil, WhatsApp se está convirtiendo en un canal muy útil para las administraciones locales.

"La ciudadanía está muy satisfecha con el servicio porque les permite estar informados de la actividad municipal y a la vez pueden contactar con el ayuntamiento muy fácilmente" (AP17).

"La principal ventaja es la posibilidad de poder tener una vía de comunicación rápida e instantánea con los vecinos, llegando a un público mucho más amplio" (AP11).

"Las redes fomentan una comunicación útil y muy efectiva. Puedes estar conectado al minuto uno con tu administración" (AM80).

A diferencia de otras plataformas digitales, WhatsApp llega directamente a los dispositivos de los usuarios sin necesidad de que estos abran la aplicación para poder recibir la información. Además, la 
ventaja de que el contenido se envíe de dispositivo a dispositivo y que no se publique en un entorno abierto donde también aparecen mensajes lanzados por otros usuarios permite a las instituciones locales que sus mensajes lleguen de forma inmediata y efectiva a sus destinatarios.

"Si el uso de las redes era un paso adelante, pensamos que WhatsApp aún es mejor. En las redes tienes que acceder, en cambio el WhatsApp te llega y lo utilizas continuamente" (AM9).

"Nuestro eslogan a la hora de lanzar el servicio de WhatsApp ha sido 'Recibe antes que nada la información del ayuntamiento"" (AM10).

"WhatsApp nos permite saber que el mensaje llega a los usuarios y que estos lo abren" (AM90).

La segunda motivación para el uso de WhatsApp por las corporaciones municipales radica en el alcance de esta plataforma. Este canal permite llegar a grupos de usuarios hasta ahora alejados del entorno digital. Principalmente, los entrevistados indican que el uso de WhatsApp les ha facilitado significativamente comunicarse con ciudadanos de diferentes franjas de edad a los que, por diferentes motivos, no lograban acceder mediante otras formas de comunicación. Por ejemplo, los usuarios de mayor edad, que habitualmente no utilizan plataformas digitales como Facebook o Twitter, han encontrado en los servicios móviles de mensajería instantánea como WhatsApp una herramienta comunicación más sencilla de manejar. Por otro lado, la mayor parte de ayuntamientos también indican que esta plataforma resulta muy efectiva para llegar a los jóvenes, otro de los sectores de población que tradicionalmente se mantenía alejado de la comunicación tradicionalmente emitida por las administraciones locales (Imagen 1).

"La principal razón por la que utilizamos WhatsApp es por su accesibilidad, entendida como la capacidad de poder llegar a gente que, mediante otras herramientas, no podemos llegar" (AG23).

"Hoy en día es muy raro que haya alguien que diga que no tiene o no conoce WhatsApp. Es algo que tenemos todos, independientemente de la edad, pero especialmente sectores más alejados de la administración, como los jóvenes" (AG15).

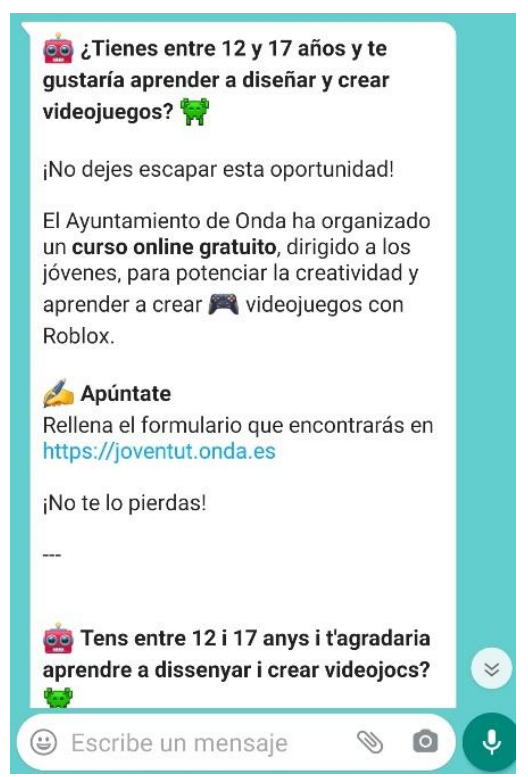

Imagen 1: Ejemplo de información dirigida a jóvenes 
Por último, la tercera motivación para la adopción de WhatsApp por parte de los ayuntamientos es la posibilidad de fomentar la transparencia. Al difundir la información y su actividad pública, las administraciones locales otorgan a la ciudadanía un mayor conocimiento, no solo de las acciones impulsadas por el gobierno local, sino de otras cuestiones que pueden llegar a influirles o mejorar su vida cotidiana: ayudas económicas, eventos culturales, nuevas infraestructuras, ofertas de empleo, nuevas tasas, etc. Esto, según los entrevistados, repercute en un incremento de la confianza ciudadana hacia la administración local.

"WhatsApp ha permitido vislumbrar que el ayuntamiento trabaja por el pueblo y da un servicio" (AP37).

"El balance que hacemos de WhatsApp es muy positivo ya que ha democratizado la información hacia el pueblo. 'Han dicho en el WhatsApp del pueblo que...' es una de las frases que más escuchamos ahora” (AP21).

"Si te preguntan es porque confian en ti (AM9).

"Si un ciudadano emite una solicitud o una reclamación, recibe respuesta y después ve resultados, la sensación de confianza se multiplica" (AG18).

El análisis de las entrevistas permite observar cómo los objetivos de los ayuntamientos respecto al uso de WhatsApp tienen como vértice a la ciudadanía y la mejora constante de la comunicación como un servicio prioritario. Sin embargo, se advierte que su uso todavía cuenta con ciertas limitaciones a solventar en relación a la organización, gestión y planificación de este servicio móvil de mensajería instantánea.

Tabla 2. Resumen de los resultados de las motivaciones de las administraciones públicas en el uso de WhatsApp

\begin{tabular}{|c|c|}
\hline \multicolumn{2}{|c|}{ Principales motivaciones detectadas } \\
\hline $\begin{array}{l}\text { 1. Comunicación directa e } \\
\text { inmediata }\end{array}$ & $\begin{array}{l}\text { - El ayuntamiento envía el contenido sin necesidad de } \\
\text { intermediarios. } \\
\text { - Los mensajes llegan directamente a los dispositivos de los } \\
\text { usuarios, sin necesidad de abrir la aplicación. } \\
\text { - Las administraciones pueden comprobar si la información } \\
\text { ha llegado a sus destinatarios. } \\
\text { - Los ciudadanos pueden presentar sus dudas o cuestiones sin } \\
\text { necesidad de acudir presencialmente a la administración o } \\
\text { ser atendidos por una persona física. } \\
\text { - Especialmente útil en información de última hora o } \\
\text { emergencias. }\end{array}$ \\
\hline 2. Mayor alcance de usuarios & $\begin{array}{l}\text { - Comunicación con ciudadanos de diferentes franjas de edad } \\
\text { a los que, por diferentes motivos, no se lograba acceder } \\
\text { mediante otras formas de comunicación (personas mayores } \\
\text { y jóvenes) }\end{array}$ \\
\hline 3. Transparencia de la institución & $\begin{array}{l}\text { - Al difundir la información y su actividad pública, otorgan a } \\
\text { la ciudadanía un mayor conocimiento de las acciones del } \\
\text { gobierno y de información que les afecta directamente. } \\
\text { - Puede generar una mayor confianza ciudadana hacia la } \\
\text { administración local. }\end{array}$ \\
\hline
\end{tabular}

Fuente: elaboración propia 


\subsection{Planteamiento y empleo de WhatsApp por parte de los ayuntamientos: forma, contenido e interacción de los mensajes}

Los resultados demuestran que los ayuntamientos tienden a priorizar, habitualmente, la sencillez y agilidad a hora de dar de alta a los ciudadanos en esta plataforma digital. La mayor parte de los ayuntamientos consultados de pequeño y mediano tamaño señalan que no establecen requisitos específicos a la hora de suscribir a los usuarios que manifiesten su voluntad de darse de alta a través de su dispositivo móvil. Tan solo algún ayuntamiento grande dispone de un formulario de inscripción (físico o electrónico) en el que se solicitan los datos personales del potencial usuario para formalizar su alta en el servicio.

Por lo general, y con el objetivo de cumplir la legislación relativa a la protección de datos, al tiempo que se facilita la accesibilidad al servicio, el procedimiento se concreta con el envío por parte del ciudadano de un mensaje anónimo con la palabra "alta" desde su móvil y sin ninguna identificación personalizada. Sin otro elemento de control añadido, se le asigna un número de identificación. De este modo, cualquiera puede darse de alta, aunque no esté empadronado en el municipio correspondiente. Asimismo, prácticamente todos los ayuntamientos tienen diferentes listas de difusión. Según los entrevistados, esta herramienta facilita el envío masivo de un mismo mensaje o archivo a varios contactos a la vez - hasta 256 como límite por envío- y permite que los usuarios reciban la información como un mensaje individual.

Cancelar la suscripción al servicio es, por lo general, igualmente sencillo. Tan solo hay que solicitarlo de forma explícita a través de un mensaje enviado al ayuntamiento. Los entrevistados apuntan que los casos en los que los ayuntamientos han tenido que bloquear o dar de baja a un usuario por un mal uso son excepcionales. Ninguno de los entrevistados destaca haber recibido mensajes con un lenguaje inapropiado o insultos por esta plataforma. En el caso que este tipo de situaciones se produzcan, coinciden en que hay que dar de baja o bloquear a estos usuarios, aunque nunca si las críticas son respetuosas.

"No hay requisitos para darse de alta ya que es como otro medio de comunicación, en este caso público y gratuito. No se difunde información sensible" (AP27).

"No existen límites a la hora de inscribirse en este servicio. Tan solo se solicita el número de teléfono y el nombre del usuario" (AP11).

"Con la misma facilidad que muchas personas se dan de alta en verano, se dan de baja de este servicio al finalizar las vacaciones" (AP37).

Respecto a la planificación y organización del departamento o la persona que se ocupa de este servicio móvil de mensajería instantánea, las entrevistas revelan que en los ayuntamientos pequeños se realiza una planificación estratégica mínima e irregular. En ocasiones, la precariedad en la planificación apunta directamente a una falta de una estrategia global en la gestión de WhatsApp. En otras, estas limitaciones se deben al escaso personal dedicado a las tareas comunicativas en los consistorios o bien por falta de formación específica en comunicación digitales de los responsables de este servicio.

Por ejemplo, resulta singular observar cómo en alguna de las administraciones locales más pequeñas la persona que gestiona íntegramente este servicio de comunicación es el alcalde o alcaldesa del municipio (Zurutuza-Muñoz \& García-Herrer, 2021), o bien se deriva en algún regidor. En estos casos, la dedicación a estas tareas es voluntaria y la formación del encargado de este canal de comunicación se basa exclusivamente en su experiencia diaria y particular como usuario de 
WhatsApp. Consecuentemente, y según los entrevistados, en los ayuntamientos pequeños no se analizan o estudian en profundidad los resultados y tan solo se revisan puntualmente los datos que ofrece la propia aplicación.

Por el contrario, los ayuntamientos grandes destacan por tener, como mínimo, un técnico o bien con un departamento de comunicación o empresa externa experta en social media, que se dedica profesionalmente a la gestión de este servicio. En estos ayuntamientos se observa una planificación estratégica previa más elaborada (programación de contenidos, estrategia y calendarios de publicación, reuniones semanales, entre otras). También realizan un análisis de los resultados con el objetivo de mejorar este servicio constantemente.

Pese a los diferentes grados de profesionalización e independientemente del tamaño de la ciudad, todos los ayuntamientos coinciden en señalar como criterio básico en no saturar, no molestar y no ser intrusivo a la hora de publicar contenidos en su WhatsApp institucional.

"No hay un día establecido para el envío. Los mensajes se lanzan según necesidad y la actualidad de municipio. Se suelen publicar en horario laboral, intentando no molestar el descanso de los vecinos ni ser intrusivo" (AP11).

"WhatsApp es una buena tecnología si está en buenas manos. Por eso la llevo yo [alcalde], aunque el pueblo no lo sabe. Por nuestra parte, no hay planificación estratégica, nos regimos por la lógica" (AP45).

"El ayuntamiento estableció unas pautas para no saturar y controlar las publicaciones. Por ejemplo, nosotros contamos con un calendario: los lunes informamos sobre farmacias de guardia, los martes sobre programación cultural, los jueves información deportiva, etc." (AM3).

"Los lunes nos reunimos con los gestores municipales para planificar la comunicación semanal y concretar qué se publicará en WhatsApp. Tenemos una estrategia definida: los jueves adelantamos la agenda del fin de semana y los viernes enviamos un resumen de prensa de la semana" (AM9).

Un punto en el que coinciden todos los ayuntamientos entrevistados es en la tipología de contenidos publicados a través de este servicio móvil de mensajería instantánea. Así, la información de servicio es aquella que se difunde a través de esta plataforma. Se trata de información con una utilidad directa para los suscritos y que ayuda a fomentar la relación entre administración y ciudadanos, así como la transparencia en la gestión del ayuntamiento. Aquí se incluyen los mensajes sobre horarios de servicios municipales, actividades culturales, turísticas y de ocio, ofertas de empleo, subvenciones o campañas de concienciación ciudadana, entre otras (Imagen 2). 

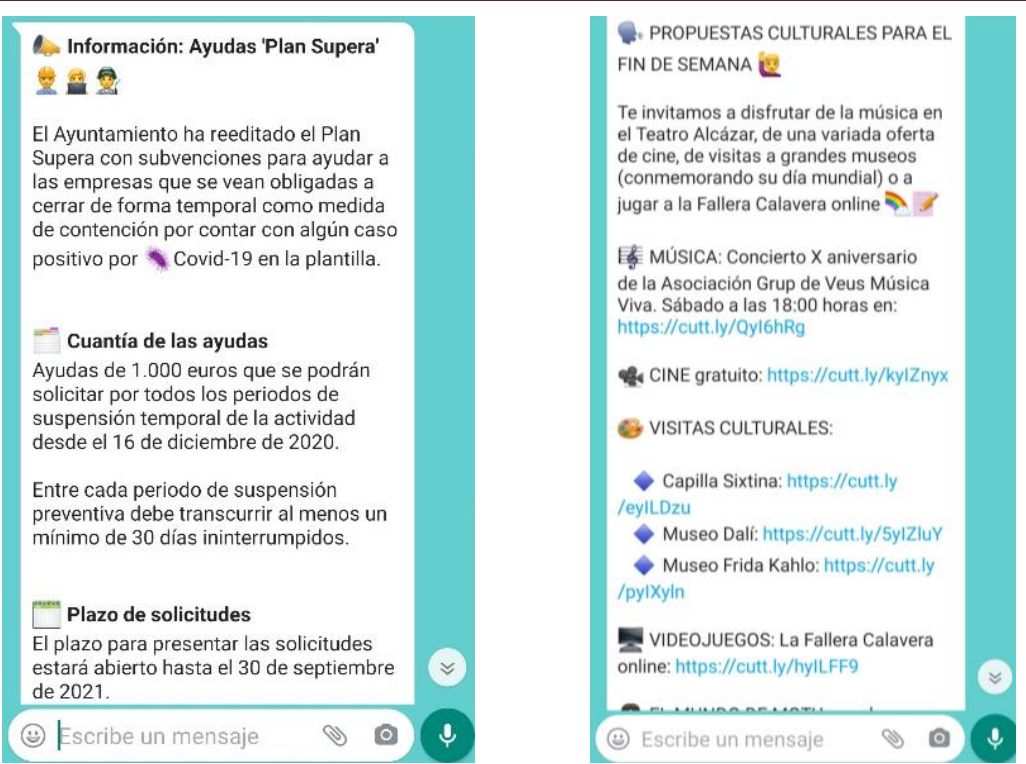

\section{Imagen 2: Ejemplo de información de servicio}

La totalidad de entrevistados subraya que nunca se hace un uso partidista del WhatsApp del ayuntamiento. No se difunden contenidos directamente relacionados con ningún partido político. Tampoco se informa ni de los logros del partido en el gobierno ni de los errores de la oposición. La postura, en este sentido, es unánime, y se advierte que difundir contenidos de propaganda política o información partidista sería un error que pagarían muy caro.

"Publicamos información general para el pueblo, nunca lo utilizamos como una herramienta política" (AP27).

"El objetivo de WhatsApp no es vender gestión o destacar los logros políticos" (AM80).

En relación a los contenidos publicados, también resulta significativo destacar cómo durante el Estado de Alarma establecido por la COVID-19 las administraciones locales no solo han publicado en WhatsApp un mayor número de mensajes diarios que en cualquier periodo ordinario, sino que estos se han adaptado a las necesidades informativas que planteaba la nueva situación. En este sentido, se ha priorizado la información relativa a las nuevas medidas, consejos higiénico-sanitarios o comunicados difundidos desde fuentes oficiales externas al municipio (Ministerio de Sanidad, Generalitat, etc.). Solo en casos muy puntuales, y principalmente en los ayuntamientos pequeños, también se ha empleado WhatsApp como un canal para informar a los vecinos de las defunciones o fecha de los sepelios, entre otros (Imagen 2).

Además, los entrevistados coinciden al apuntar que en este periodo excepcional se han recibido más altas de usuarios que en cualquier otro momento desde la puesta en marcha de este canal de comunicación municipal. Esto demuestra el interés por la información generado por la pandemia del Coronavirus (Casero-Ripollés, 2020b; Pérez-Curiel \& Velasco-Molpeceres, 2020).

"La COVID-19 trastocó nuestra programación. Tuvimos que ser más rápidos y rigurosos en la información que publicamos en WhatsApp y nos obligó a coordinarnos con la policía para difundir información" (AM3).

"Durante la pandemia la frase el ayuntamiento es la institución más cercana, fue cierta. Nos adaptamos a los nuevos hábitos de los ciudadanos. Por ejemplo, además de informar procuramos enviar contenidos con un tono optimista y muy visuales" (AM10). 
"La adaptación fue poco a poco, pero durante la COVID-19 el repunte más significativo en el número de contenidos llegó cuando comenzamos a publicar las defunciones, siempre que las familias lo autorizaban" (AP21).

En relación al estilo de los mensajes que se difunden a través de WhatsApp, la mayoría de las administraciones locales coinciden en trabajar por adaptar los contenidos a las características de uso del móvil y a las posibilidades formales que ofrece la aplicación. Así, gran parte de los ayuntamientos tienden a difundir mensajes breves, sencillos y con un lenguaje cercano. Para reforzar estas características se suelen incluir recursos gráficos como emoticonos u otros útiles propios del entorno digital, privilegiando también los enlaces que redirigen a las webs municipales y permiten que el ciudadano amplíe o profundice en la información.

La mayoría de administraciones locales apuestan por incluir en sus mensajes diferentes recursos gráficos (fotografía, video, cartel, captura de pantalla, gift, etc.) para priorizar el consumo y la comprensión de sus comunicaciones. Sin embargo, algunos advierten que usar estos recursos supone un problema en la difusión de sus mensajes. El "peso" de las imágenes en el envío, ralentiza y dificulta que el usuario pueda descargarse correctamente el contenido. Algo que es percibido como una limitación.

"En WhatsApp hablamos de tú porque es importante que se cree complicidad [con los usuarios] y que sea familiar" (AM9).

"Intentamos adaptarnos al lenguaje digital. En ocasiones, emitimos el mismo tema en diversas redes sociales, pero en cada una de ellas el formato del mensaje es distinto, adaptado a sus propias particularidades" (AP17).

"Nos dimos cuenta que las imágenes saturaban el móvil de los ciudadanos y que para llegar mejor era más interesante publicar en .pdf" (AM3).

Un aspecto clave del canal de WhatsApp de los ayuntamientos es el grado de interacción que se establece con la ciudadanía. Pese a las potencialidades de esta herramienta para fomentar un diálogo directo entre administración y usuarios, la mayoría de los consistorios coinciden en calificar a WhatsApp como un canal eminentemente informativo y de servicio público en el que es muy complicado alcanzar una bidireccionalidad real y un diálogo efectivo.

Mayoritariamente su uso es exclusivamente unidireccional debido, principalmente, a dos motivos. En primer lugar, los ayuntamientos ya cuentan con otras herramientas más institucionales para responder y dialogar con los ciudadanos. Por ejemplo, mediante apps desarrolladas por la administración o bien a través de la web. En segundo lugar, la escasez de recursos humanos y equipos de comunicación destinados a la gestión de esta plataforma digital no puede garantizar una bidireccionalidad efectiva. Por ello, no hay garantías que los mensajes de queja, preguntas o dudas que se reciben en WhatsApp se puedan responder. Como máximo, los ayuntamientos que cuentan con un equipo de comunicación, suelen contestar con mensajes tipo, o bien redireccionando a otras fuentes de información como las webs institucionales.

"Utilizamos WhatsApp como una herramienta unidireccional. Sería muy útil tener feedback con los ciudadanos, pero tendría que reforzarse el gabinete de comunicación" (AM9).

"El uso es unidireccional. Para conseguir responder a las preguntas, quejas o denuncias, se necesitaría por lo menos una persona que se dedicara en exclusiva a esta tarea. En un ayuntamiento de estas dimensiones es imposible" (AP21). 
"La comunicación es, evidentemente, unidireccional. De otro modo sería una locura. Para contestar contamos con otras vías como el Buzón del Ciudadano o la App Línea Verde" (AP37).

"Comenzamos queriendo contestar, pero era imposible. Para encontrar la respuesta a una pregunta podíamos estar media mañana. Ahora se avisa desde el inicio que es unidireccional, que no se trata de un chat de debate o un buzón para reclamaciones" (AM3).

Cabe destacar que esta comunicación unidireccional supone, en algunas ocasiones, una problemática para las administraciones locales. Según indican los entrevistados, pese a que al dar de alta a los usuarios les informan que se trata exclusivamente de un servicio de difusión de información unidireccional, diariamente reciben mensajes de ciudadanos trasladándoles cuestiones y dudas. Muchos de estos mensajes, además, llegan en horario no laboral y en fines de semana, un hecho que dificulta más todavía ofrecer una respuesta por parte de los ayuntamientos.

"La población no acaba de comprender que es un servicio unidireccional. Si no les contestamos, insisten, aunque avisamos en la bienvenida" (AM90).

"Uno de los principales problemas observados es que en ocasiones [WhatsApp] genera mucho trabajo en horas no laborales y muchos usuarios realizan preguntas en momentos que no se puede contestar" (AP11).

Tabla 3. Resumen de los resultados sobre el planteamiento de los mensajes en WhatsApp por parte de las administraciones locales

\begin{tabular}{|c|c|}
\hline \multicolumn{2}{|c|}{ Principales características del mensaje } \\
\hline $\begin{array}{l}\text { 1. Gestión para activar o desactivar } \\
\text { el servicio de WhatsApp }\end{array}$ & $\begin{array}{l}\text { - Generalmente, los usuarios pueden darse de alta o baja del } \\
\text { servicio de WhatsApp directamente desde la propia } \\
\text { plataforma, sin realizar ningún trámite presencial. } \\
\text { - Las administraciones locales únicamente solicitan el } \\
\text { nombre y apellidos como datos identificativos. } \\
\text { - No existen límites para darse de alta en el servicio, como, } \\
\text { por ejemplo, estar empadronado en el municipio. }\end{array}$ \\
\hline 2. Periodicidad & $\begin{array}{l}\text { - Las administraciones públicas suelen enviar sus mensajes en } \\
\text { horario laboral, a excepción de información de última hora } \\
\text { o emergencias. } \\
\text { - Cantidad de mensajes al día limitada para no saturar a los } \\
\text { usuarios. }\end{array}$ \\
\hline 3. Contenidos difundidos & $\begin{array}{l}\text { - Principalmente, información de servicio (horarios de } \\
\text { servicios municipales, actividades culturales, turísticas y de } \\
\text { ocio, ofertas de empleo, subvenciones o campañas de } \\
\text { concienciación ciudadana, etc.). } \\
\text { - Nunca se emplea este servicio como instrumento partidista a } \\
\text { favor del partido en el Gobierno o en contra de la oposición. }\end{array}$ \\
\hline 4. Estilo del mensaje & $\begin{array}{l}\text { - Brevedad, sencillez y lenguaje cercano a la ciudadanía. } \\
\text { - Uso habitual de recursos digitales como los enlaces. } \\
\text { - Empleo controlado de recursos visuales como fotografías, } \\
\text { vídeos o carteles, entre otros. }\end{array}$ \\
\hline 5. Interacción & - Principalmente, uso unidireccional de WhatsApp. \\
\hline
\end{tabular}

Fuente: elaboración propia 


\subsection{Limitaciones y retos futuros en el uso del WhatsApp por parte de las administraciones públicas}

El uso de WhatsApp por parte de las administraciones públicas resulta, en algunas ocasiones, una práctica que no se encuentra exenta de dificultades. Por este motivo, gran parte de los responsables de los ayuntamientos entrevistados indican encontrarse en un punto intermedio en el empleo de esta plataforma y señalan diversos retos a alcanzar a medio o largo plazo. Concretamente, destacan tres desafíos pendientes.

El primer reto planteado es el de conseguir un mayor número de usuarios registrados en el servicio de WhatsApp. Pese a que en este último año marcado por la emergencia sanitaria de la COVID-19 el número de altas ha crecido de forma significativa, todavía existen sectores de población a los que es difícil llegar. Este es el caso de la población con mayor edad, quienes en general, desconocen las pautas de funcionamiento de los dispositivos y aplicaciones móviles como WhatsApp. Otra de las franjas de edad con reticencias en el uso de este canal de comunicación política institucional son los jóvenes. Según los entrevistados, los adolescentes todavía ven la información institucional muy alejada de sus propios intereses y señalan que aún existe un gran desconocimiento sobre este servicio municipal y sobre los contenidos que se ofrecen.

"Queremos hacer más campañas para que la gente se apunte y le pueda llegar la información directamente a su móvil. El objeto o reto es que todo el pueblo esté conectado y reciba la información" (AM9).

"El reto es tener un 59-60\% del público en el WhatsApp. Ahora tenemos un problema por desconocimiento de nuestro canal de WhatsApp" (AM3).

"El perfil [de usuarios] es muy concreto: gente de 35 a 55 años con niños. Los jóvenes creen que es muy institucional y no va con ellos. Tampoco entran los muy mayores. Tenemos prevista una iniciativa para ir al hogar de los jubilados y que una persona les enseñe a entrar y manejarse. También en el mercado y en el instituto" (AM80).

Un segundo desafío es el de personalizar la información que se difunde por WhatsApp. Actualmente, todos los ayuntamientos entrevistados ofrecen el mismo contenido a través de todas las listas de difusión que tienen activas, independientemente de la temática o las características de los destinatarios. Sin embargo, la segmentación de los usuarios mediante la creación de distintas listas de distribución en base a determinados tipos de intereses o características demográficas, podría ser un aliciente para el uso de este servicio. Así, los ciudadanos podrían suscribirse a aquellas listas que difundan información sobre sus gustos o preocupaciones.

"En el futuro se podrían crear listas de difusión por intereses de cada persona, sectorializar la comunicación de WhatsApp... pero ahora es complicado" (AP45).

"La idea es automatizar y crear diferentes buzones de WhatsApp para las diferentes concejalías" (AM9).

Por último, uno de los principales desafíos es la mejora de la planificación y coordinación de este servicio. En este sentido, pese a que el balance en el uso de esta aplicación es positivo, la mayor parte de los ayuntamientos reconocen la dificultad de poder mantener un ritmo de publicaciones constante. Además, también es problemático poder motivar a los demás miembros del consistorio para que se impliquen, propongan ideas y contenidos para compartir con la ciudadanía. Esto afecta principalmente a los ayuntamientos pequeños, dónde, por lo general, no existen profesionales de la comunicación que gestionen los contenidos de esta aplicación y la relación con los usuarios. 
"Las plataformas digitales requieren tiempo, tener actualizada toda la información, poder atender a todos los mensajes que se reciben, y eso es lo que todavía no lo tenemos. Además de una dedicación diaria, este tipo de servicios requiere una actualización constante y, eso requiere estar constantemente generando noticias e información" (AG15).

"Uno de los grandes retos futuros es que la gestión de este tipo de servicio debería ser una estrategia que implicara a toda la organización, no solo a un área concreta" (AG15).

"Se podría dar un mejor servicio. Hay que asentar una estrategia. Nos hace falta más calma y sentarnos a reflexionar" (AM3).

Tabla 4. Resumen de los resultados de los retos futuros de las administraciones públicas en el uso de WhatsApp

\begin{tabular}{|l|l|}
\hline \multicolumn{2}{|l|}{ Principales retos planteados } \\
\hline 1. Aumento de usuarios inscritos & $\begin{array}{l}\text { - Las administraciones locales buscan ampliar el número de } \\
\text { inscritos, especialmente, dentro de grupos de edad más } \\
\text { alejados de la información institucional. }\end{array}$ \\
\hline $\begin{array}{l}\text { 2. Personalización de la } \\
\text { información }\end{array}$ & $\begin{array}{l}\text { Segmentación de los usuarios en listas de distribución por } \\
\text { temáticas. Los usuarios pueden suscribirse solo en aquellas } \\
\text { acordes a sus intereses. }\end{array}$ \\
\hline 3. Planificación estratégica & $\begin{array}{l}\text { Mejora de la planificación y coordinación del servicio: } \\
\text { publicación periódica de contenidos, estilo homogéneo del } \\
\text { mensaje, aprovechamiento de las potencialidades del } \\
\text { entorno digital y mayor índice de respuesta. } \\
\text { - Implicación de toda la administración local para aumentar } \\
\text { recursos humanos dedicados al servicio y mayor diversidad } \\
\text { de contenidos que incluyan todos los ámbitos de acción del } \\
\text { gobierno local. }\end{array}$ \\
\hline
\end{tabular}

Fuente: elaboración propia

\section{Discusión y conclusiones}

Los resultados indican que WhatsApp se ha convertido en una herramienta esencial para las administraciones locales. En los últimos años, tanto los ayuntamientos grandes, como aquellos más pequeños, se están adaptando a las potencialidades de esta plataforma digital. Así, la han incorporado a su estrategia comunicativa habitual, transformando sus propias rutinas productivas y sustituyendo otras formas más tradicionales de comunicación institucional.

Nuestros hallazgos permiten identificar las tres principales razones que han llevado a las administraciones locales a adoptar este tipo de plataformas digitales. En primer lugar, la posibilidad de poder abrir una vía de contacto directo e inmediato con la ciudadanía. Las características de WhatsApp provocan que las instituciones locales vean en esta plataforma una de las más efectivas para asegurar que sus mensajes llegan correctamente a la ciudadanía. Paralelamente, la posibilidad que tienen los ciudadanos para trasladar sus dudas o cuestiones sin necesidad de tener que acudir presencialmente al ayuntamiento resultan un aliciente para el uso de esta aplicación. En segundo lugar, la posibilidad de ampliar el público de la comunicación política institucional, especialmente del tradicionalmente alejado del entorno digital, como las personas mayores, o incluso de la propia institución pública, como los más jóvenes. Por último, la posibilidad de difundir información sobre su gestión y actividad diaria ha hecho que los ayuntamientos hayan identificado en WhatsApp un instrumento imprescindible para cumplir con los estándares de transparencia y responsabilidad 
institucional. Estos hallazgos permiten afirmar que esta plataforma digital es percibida por las administraciones locales como una forma para mejorar y favorecer la prestación de su servicio público y su imagen. Esta característica les permite potenciar la confianza ciudadana en la gestión municipal, coincidiendo así con lo apuntado por la literatura previa (Van Dijck, et al., 2018; SimelioSolà \& Rodríguez Navas, 2014).

Otro hallazgo importante respecto al empleo de WhatsApp por parte de las administraciones locales demuestra que, pese a que todas ellas hacen un balance muy positivo de su experiencia en esta plataforma, algunas expresan carencias en la planificación estratégica del servicio. Estas limitaciones se dan, principalmente, en los municipios más pequeños, aquellos que no cuentan con profesionales o departamentos de comunicación expertos en social media (Criado, et al., 2017). Este déficit de recursos humanos impide a las corporaciones programar sus publicaciones con una periodicidad, plantear una variedad de contenidos respecto a otras redes sociales o fijar un modelo de mensaje adaptado a las potencialidades de cada plataforma. Así, mientras que los ayuntamientos grandes plantean un uso basado en una planificación estratégica predeterminada, los pequeños no. En este último caso, los conocimientos y funciones de este servicio móvil de mensajería instantánea vienen determinados por la propia experiencia de los gestores como usuarios.

Esta diferencia en la planificación desaparece en los contenidos. Todos los ayuntamientos focalizan el uso de WhatsApp como vía para transmitir información de servicio público, es decir, cuestiones que afectan a la vida cotidiana de la ciudadanía. En ningún caso, se utiliza este canal con una lógica partidista. Es decir, no se informa de actividades directamente relacionadas con ningún partido político, ni de los logros del partido en el gobierno o los errores de la oposición. Únicamente se vehiculan mensajes relativos a la agenda de actividades de ocio, horarios de servicios municipales, ofertas de empleo o subvenciones, entre otras cuestiones.

Otro resultado relevante es la falta de bidireccionalidad. Pese a sus posibilidades técnicas, los ayuntamientos no usan su canal de WhatsApp para dialogar o interactuar con la ciudadanía. Por el contrario, apuestan por configurar esta plataforma digital desde una perspectiva unidireccional como una vía de envío de información de arriba abajo, desde la administración a la ciudadanía. La falta de personal y recursos para garantizar una atención personalizada en las respuestas a los ciudadanos es el motivo principal aportado por las administraciones locales. Esta concepción coincide con lo detectado por investigaciones previas en otros medios sociales de las instituciones públicas como Facebook o Twitter (Solito \& Materassi, 2020; De Widt \& Panagiotopoulos, 2018; Criado, et al., 2017). Con ello, se desaprovecha la conectividad social, una de las principales cualidades de las plataformas digitales.

En este marco, los servicios móviles de mensajería instantánea están contribuyendo a extender la plataformización en la comunicación política institucional. Los ayuntamientos no solo han adoptado los canales de WhatsApp como una vía de contacto directo e inmediato con la ciudadanía (ZurutuzaMuñoz \& García Herrer, 2021) sino que los han incorporado como un instrumento para mejorar su servicio público. En este sentido, aplicaciones como WhatsApp se sitúan en el centro de la comunicación política institucional cada vez con más fuerza, pues permiten a las administraciones empezar a ejercer modelos de gobierno mejor comunicados, transparentes y más cercanos a los ciudadanos. Habrá que analizar, en nuevas investigaciones, si esto provoca una reorganización de las prácticas, rutinas y dinámicas de este campo para calibrar hasta qué punto la plataformización es capaz de transformar la manera de hacer comunicación política por parte de las instituciones públicas locales. 


\section{Referencias}

Aguado, J. M., \& Martínez, I. J. (2008). La comunicación móvil en el ecosistema informativo: de las altertas SMS al mobile 2.0. Trípodos, (23), pp. 107-118.

Asociación para la Investigación de Medios de Comunicación - (AIMC, 2020). Encuesta AIMC a usuarios de Internet - Navegantes en la Red. Recuperado de https://www.aimc.es/otros-estudiostrabajos/navegantes-la-red/

Bayer, J. B., Campbell, S. W., \& Ling, R. (2016). Connection cues: Activating the norms and habits of social connectedness. Communication Theory, 26(2), pp. 128-149.

https://doi.org/10.1111/comt.12090

Bennett, W. L., \& Segerberg, A. (2012). The logic of connective action: Digital media and the personalization of contentious politics. Information, communication \& society, 15(5), pp. 739768. https://doi.org/10.1080/1369118X.2012.670661

Bertot, J. C., Jaeger, P. T., \& Grimes, J. M. (2010). Using ICTs to create a culture of transparency: Egovernment and social media as openness and anti-corruption tools for societies. Government information quarterly, 27(3), 264-271. https://doi.org/10.1016/j.giq.2010.03.001

Bimber, B. (2014). Digital media in the Obama campaigns of 2008 and 2012: Adaptation to the personalized political communication environment. Journal of information technology \& politics, 11(2), pp. 130-150. https://doi.org/10.1080/19331681.2014.895691

Bonsón, E., Royo, S., \& Ratkai, M. (2015). Citizens' engagement on local governments' Facebook sites. An empirical analysis: The impact of different media and content types in Western Europe. Government information quarterly, 32(1), pp. 52-62. https://doi.org/10.1016/j.giq.2014.11.001

Bonsón, E., Torres, L., Royo, S., \& Flores, F. (2012). Local e-government 2.0: Social media and corporate transparency in municipalities. Government information quarterly, 29(2), 123-132. https://doi.org/10.1016/j.giq.2011.10.001

Bossetta, M. (2018). The digital architectures of social media: Comparing political campaigning on Facebook, Twitter, Instagram, and Snapchat in the 2016 US election. Journalism \& mass communication quarterly, 95(2), pp. 471-496. https://doi.org/10.1177/1077699018763307

Bretschneider, S., \& Parker, M. (2016). Organization formalization, sector and social media: Does increased standardization of policy broaden and deepen social media use in organizations? Government Information Quarterly, 33(4), pp. 614-628. https://doi.org/10.1016/j.giq.2016.09.005

Campillo-Alhama, C. (2010). Comunicación pública y administración municipal: una propuesta de modelo estructural. Pensar la Publicidad. Revista Internacional de Investigaciones Publicitarias, 4(1), pp. 45-62. ISSN 1887-8598.

Casero-Ripollés, A. (2020a). Servicios móviles de mensajería instantánea y Covid-19: oportunidades y limitaciones para la comunicación institucional. Anuario ThinkEPI, 14, e14d05. https://doi.org/10.3145/thinkepi.2020.e14d05 
Casero-Ripollés, A. (2020b). Impact of Covid-19 on the media system. Communicative and democratic consequences of news consumption during the outbreak. Profesional de la Información, 29(2), e290223. https://doi.org/10.3145/epi.2020.mar.23

Castells, M. (2017). Ruptura. La crisis de la democracia liberal. Madrid: Alianza.

Castillo-Esparcia, A., Fernández-Souto, A. B., \& Puentes-Rivera, I. (2020). Political communication and Covid-19: strategies of the Government of Spain. Profesional de la información, 29(4), e290419. https://doi.org/10.3145/epi.2020.jul.19

Castro Martínez, A., Morán Urdiales, I., \& Díaz Morilla, P. (2021). Comunicación institucional de crisis y redes sociales en la Covid-19: los casos de Yunquera y Gaucín. Ámbitos: revista internacional de comunicación, 52, pp. 102-123.

Criado, J. I., \& Villodre, J. (2021). Delivering public services through social media in European local governments. An interpretative framework using semantic algorithms. Local government studies, 47(2), 253-275. https://doi.org/10.1080/03003930.2020.1729750

Criado, J. I., Pastor, V., \& Villodre, J. (2017). Redes Sociales Digitales en los Ayuntamientos Españoles. Dinámicas de adopción, estrategias de implementación, usos y recursos. Colección NovaGob Academia, 2 (mayo). Colección NovaGob Academia, (2).

De Widt, D., \& Panagiotopoulos, P. (2018). Informal networking in the public sector: Mapping local government debates in a period of austerity. Government Information Quarterly, 35(3), pp. 375388.

Feenstra, R. A., Tormey, S., Casero-Ripollés, A., \& Keane, J. (2017). Refiguring democracy. The Spanish political laboratory. Nueva York: Routledge.

Fernández, R. (2018). El móvil como propagador de las revueltas en Irán de diciembre de 2019. El caso de la red social Telegram. En: Langa, C. y Ballesteros-Aguayo, L. (Eds.), Movimientos populistas en Europa: la actualización del discurso totalitario en los medios de comunicación actuales y su repercusión en la opinión pública. (pp. 123-137). Egregius.

Fuchs, C. (2014). Medios sociales y esfera pública. Telos. Revista de Pensamiento sobre Comunicación, Tecnología y Sociedad, 96, pp. 71-82.

García-Santamaría, J. V., Pérez-Serrano, M. J., \& Rodríguez-Pallares, M. (2020). Portavoces oficiales y estrategia audiovisual en la crisis de la Covid-19 en España. Profesional de la información, 29(5). https://doi.org/10.3145/epi.2020.sep.13

Gil de Zúñiga, H., Ardèvol-Abreu, A., \& Casero-Ripollés, A. (2021). WhatsApp political discussion, conventional participation and activism: exploring direct, indirect and generational effects. Information, Communication \& Society, 24(2), 201-218. https://doi.org/10.1080/1369118X.2019.1642933

Gillespie, T. (2018). Regulation of and by platforms. En: J. Burgess, A. Marwick, y T. Poell (Eds.), Sage Handbook of Social Media (254-278). London: Sage. 
Graham, M., \& Avery, E. (2013). Government public relations and social media: An analysis of the perceptions and trends of social media use at the local government level. Public Relations Journal, 7(4), 1-21. ISSN 1942-4604.

Guillamón, M. D., Ríos, A. M., Gesuele, B., \& Metallo, C. (2016). Factors influencing social media use in local governments: The case of Italy and Spain. Government Information Quarterly, 33(3), 460-471. https://doi.org/10.1016/j.giq.2016.06.005

Gutiérrez-Rubí, A. (2015). La transformación digital y móvil de la comunicación política. Madrid, España: Fundación Telefónica.

Instituto Nacional de Estadística - INE (2020). Encuesta sobre Equipamiento y Uso de Tecnologías de Información y Comunicación en los Hogares del Instituto Nacional de Estadística. Recuperado de:

https://www.ine.es/dyngs/INEbase/es/operacion.htm?c=estadistica_C\&cid=1254736176741\&men $\underline{\mathrm{u}=\mathrm{ultiDatos} \& \mathrm{idp}=1254735976608}$

Karpf, D., Kreiss, D., Nielsen, R. K., \& Powers, M. (2015). Qualitative Political Communication Introduction The role of qualitative methods in political communication Research: Past, present, and future. International Journal of Communication, 9(19), pp. 1888-1906.

Lee, H., Kwak, N., Campbell, S. W., \& Ling, R. (2014). Mobile communication and political participation in South Korea: Examining the intersections between informational and relational uses. Computers in Human Behavior, 38, pp. 85-92. https://doi.org/10.1016/j.chb.2014.05.017

Lev-On, A., \& Steinfeld, N. (2015). Local engagement online: Municipal Facebook pages as hubs of interaction. Government information quarterly, 32(3), pp. 299-307.

https://doi.org/10.1016/j.giq.2015.05.007

Ling, R. (2017). The social dynamics of mobile group messaging. Annals of the International Communication Association, $41(3-4), \quad$ pp. 242-249. https://doi.org/10.1080/23808985.2017.1374199

López-Tárraga, A. B. (2020). Comunicación de crisis y Ayuntamientos: el papel de Telegram durante la crisis sanitaria de la COVID-19. RAEIC, Revista de la Asociación Española de Investigación de la Comunicación, 7(14), pp. 104-126. https://doi.org/10.24137/raeic.7.14.5

Malka, V., Ariel, Y., \& Avidar, R. (2015). Fighting, worrying and sharing: Operation 'Protective Edge'as the first WhatsApp war. Media, War \& Conflict, 8(3), pp. 329-344. ttps://doi.org/10.1177/1750635215611610

Manfredi-Sánchez, J. L. (2017). Horizontes de la información pública. Profesional De La Información, 26(3), 353-360. https://doi.org/10.3145/epi.2017.may.01

Mickoleit, A. (2014). Social media use by governments: A policy primer to discuss trends, identify policy opportunities and guide decision makers. OECD Working Papers on Public Governance, (26), OECD Publishing, Paris. https://doi.org/10.1787/5jxrcmghmk0s-en 
Newman, N.; Fletcher, R.; Kalogeropoulos, A.; \& Nielsen, R. K. (2019). Reuters Institute Digital News Report 2019. Reuters Institute for the Study of Journalism. Recuperado de: http://twixar.me/nPB1

Nieborg, D. B., \& Poell, T. (2018). The platformization of cultural production: Theorizing the contingent cultural commodity. New media \& society, 20(11), 4275-4292. https://doi.org/10.1177/1461444818769694

Pérez-Curiel, C. \& Velasco-Molpeceres, A. M. (2020). Impacto del discurso político en la difusión de bulos sobre Covid-19. Influencia de la desinformación en públicos y medios. Revista Latina de Comunicación Social, 78, 65-97. https://www.doi.org/10.4185/RLCS-2020-1469

Pintado Pérez, F. J., \& Paniagua Rojano, F. J. (2018). La Transparencia en los gobiernos y los partidos políticos: aproximación y consenso en el caso de España, adComunica, 16, pp. 111-134. http://dx.doi.org/10.6035/2174-0992.2018.16.7

Plantin, J. C., \& Punathambekar, A. (2019). Digital media infrastructures: pipes, platforms, and politics. Media, Culture \& Society, 41(2), 163-174. https://doi.org/10.1177/0163443718818376

Reddick, C. G., Chatfield, A. T. \& Ojo, A. (2017). A social media text analytics framework for double-loop learning for citizen-centric public services: A case study of a local government Facebook use. Government Information Quarterly, 34(1), pp. 110-125. https://doi.org/10.1016/j.giq.2016.11.001

Rojas, H., \& Puig-I-Abril, E. (2009). Mobilizers mobilized: Information, expression, mobilization and participation in the digital age. Journal of Computer-Mediated Communication, 14(4), 902927. https://doi.org/10.1111/j.1083-6101.2009.01475.x

Salvador, M. \& Ramírez, O. (2016). Gobierno abierto y competencias digitales: Transformando la administración pública para afrontar los retos del nuevo paradigma, Cuadernos de Gobierno y Administración Pública, 3(1), pp. 1-13.

Simelio-Solà, N. \& Rodríguez-Navas, P. M. (2014). Comunicación pública y participación ciudadana. El uso de Twitter en los ayuntamientos de Cataluña. Historia y comunicación social, 49, pp. 479-490. http://dx.doi.org/10.5209/rev_HICS.2014.v19.45043

Solito, L., \& Materassi, L. (2020). On a municipality-wide scale. Social media use in Italian municipalities: information and interaction. adComunica, 20, pp. 151-172. https://doi.org/10.6035/2174-0992.2020.20.7

Spiliotopoulou, L., Charalabidis, Y., Loukis, E. N., \& Diamantopoulou, V. (2014). A framework for advanced social media exploitation in government for crowdsourcing. Transforming Government: People, Process and Policy, 8(4), pp. 545-568. ISSN: 1750-6166.

Thelwall, M., Buckley, K., \& Paltoglou, G. (2011). Sentiment in Twitter events. Journal of the American Society for Information Science and Technology, 62(2), pp. 406-418. https://doi.org/10.1002/asi.21462 
Thorson, K., Medeiros, M., Cotter, K., Chen, Y., Rodgers, K., Bae, A., \& Baykaldi, S. (2020). Platform Civics: Facebook in the Local Information Infrastructure. Digital Journalism, 8(10), pp. 1231-1257. https://doi.org/10.1080/21670811.2020.1842776

Valeriani, A., \& Vaccari, C. (2017). Political talk on mobile instant messaging services: a comparative analysis of Germany, Italy, and the UK. Information, Communication \& Society, 21(11), pp. 1715-1731. https://doi.org/10.1080/1369118X.2017.1350730

Van Dijck, J., Poell, T., \& De Waal, M. (2018). The platform society: Public values in a connective world. Oxford University Press.

Vázquez Sande, P. (2016). Políticapp: hacia una categorización de las apps móviles de comunicación política. Fonseca, Journal of Communication, (12), pp. 59-78.

http://dx.doi.org/10.14201/fjc2016125978

Waters, R. D., \& Williams, J. M. (2011). Squawking, tweeting, cooing, and hooting: Analyzing the communication patterns of government agencies on Twitter. Journal of public affairs, 11(4), pp. 353-363. https://doi.org/10.1002/pa.385

We are social \& Hootsuit (2021). Digital 2021. Local country headlines. Recuperado de: https://datareportal.com/reports/digital-2021-local-countryheadlines?utm_source=Reports\&utm_medium=PDF\&utm_campaign=Digital_2021\&utm_content =Dual_Report_Promo_Slide

Willnat, L., Wong, W. J., Tamam, E., \& Aw, A. (2013). Online media and political participation: The case of Malaysia. Mass Communication and Society, 16(4), pp. 557-585. https://doi.org/10.1080/15205436.2012.734891

Zurutuza-Muñoz, C., \& García Herrer, I. (2021). Comunicación y participación ciudadana en municipios de concejo abierto: un caso de estudio. adComunica, 21, pp. 161-182. https://doi.org/10.6035/2174-0992.2021.21.9

\section{AUTOR/ES:}

\section{Silvia Marcos-García}

Profesora Ayudante Doctora en el Departamento de Ciencias de la Comunicación de la Universitat Jaume I de Castelló (UJI). Es Doctora en Ciencias de la Comunicación, graduada en Periodismo y Máster en Nuevas Tendencias y Procesos de Innovación en Comunicación por la UJI. Sus líneas de investigación se centran en el periodismo, las redes sociales y la comunicación política desde diferentes perspectivas que tienen en cuenta tanto la figura del periodista como la del político y ciudadano. Imparte docencia en los grados en Periodismo, Comunicación Audiovisual y Publicidad y Relaciones Públicas en asignaturas vinculadas a la información periodística en radio y televisión, así como en el Máster oficial en Nuevas Tendencias y Procesos de Innovación en Comunicación.

smarcos@uji.es

Índice H: 6

Orcid ID: http://orcid.org/0000-0003-1682-1009

Google Scholar: https://scholar.google.es/citations?user=8-h8i38AAAAJ\&hl=es

ResearchGate: https://www.researchgate.net/profile/Silvia-Marcos-Garcia

Academia.edu: https://uji.academia.edu/SilviaMarcos 


\section{Hugo Doménech-Fabregat}

Profesor Contratado Doctor del Departamento de Ciencias de la Comunicación de la Universitat Jaume I (UJI). Licenciado en Ciencias de la Información por la Universidad Pontificia de Salamanca (UPSA). Además, es Especialista Universitario en Fotografía y Arte por la Universidad Politécnica de Valencia (UPV). Sus líneas de investigación se centran en el estudio del Periodismo Digital, los Géneros Periodísticos y el Fotoperiodismo desde diferentes perspectivas. Ha participado en diferentes proyectos de investigación obtenidos en convocatorias competitivas estatales y regionales y en congresos científicos de carácter nacional e internacional. Es co-director del largometraje documental La sombra del iceberg. Autopsia a la mítica fotografía de Robert Capa (2007), premiado en diversos festivales nacionales e internacionales.

hdomenec@uji.es

Índice H: 9

Orcid ID: https://orcid.org/0000-0002-7609-8361

Google Scholar: https://scholar.google.es/citations?user=JwMNnkQAAAAJ\&hl=es\&oi=ao

ResearchGate: https://www.researchgate.net/profile/Hugo-Fabregat

Academia.edu: https://independent.academia.edu/HugoDom\%C3\%A9nechFabregat

\section{Andreu Casero-Ripollés}

Catedrático de Universidad de Periodismo en el Departamento de Ciencias de la Comunicación y Decano de la Facultad de Ciencias Humanas y Sociales de la Universitat Jaume I de Castelló. Licenciado por la Universitat Autònoma de Barcelona y Doctor por la Universitat Pompeu Fabra. Ha dirigido, como investigador principal, un total de 10 proyectos de $\mathrm{I}+\mathrm{D}$ en convocatorias competitivas. Fue coordinador para el campo de Comunicación (panel CSO) de la Agencia Española de Investigación (AEI) del Gobierno de España entre 2016 y 2019. Actualmente, es presidente del área de Ciencias Sociales de la Agencia Andaluza del Conocimiento (AAC-DEVA) en el ámbito de evaluación de la investigación. Ha realizado estancias de investigación en la Columbia University, la University of Westminster o la Università degli Studi de Firenze, entre otras. Sus líneas de investigación se centran en la comunicación política y las transformaciones digitales del periodismo. casero@uji.es

Índice H: 35

Orcid ID: http://orcid.org/0000-0001-6986-4163

Google Scholar: https://scholar.google.es/citations?user=TuiVp7MAAAAJ\&hl=es

ResearchGate: https://www.researchgate.net/profile/Andreu-Casero-Ripolles

Academia.edu: https://uji.academia.edu/AndreuCaseroRipolles 